\title{
Psychological manifestations in post myocardial infraction patients
}

\author{
Singh $S^{1}$, Kanwar $G^{2}$, Paikra $S^{3}$, Pandey $S^{4}$ \\ ${ }^{1}$ Dr. Sanjay Singh, Assistant Professor, Department of Medicine, GMC, Ambikapur, CG, ${ }^{2}$ Dr. Gopal Kanwar, Associate \\ Professor, Department of Medicine, GMC, Ambikapur, CG, ${ }^{3}$ Dr. Shashi Paikra, Demonstrator, Department of Anatomy, \\ CIMS, Bilaspur, CG, ${ }^{4}$ Dr. Sachin Pandey, Assistant Professor, Department of Community Medicine, CIMS, Bilaspur, \\ $\mathrm{CG}$, India.
}

Corresponding Author: Dr. Gopal Kanwar, Associate Professor, Department of Medicine, GMC, Ambikapur, CG. Email: drgopalskanwar@rediffmail.com.

\begin{abstract}
Background: In the past few years a very important observation that came to light is the increase in prevalence of some psychiatric disorder in chronically ill patients. Symptoms of depression and anxiety are common following myocardial infarction (MI). Both the symptoms have been linked with increased risk of recurrent coronary artery disease (CAD), Severe psychological stress, major life events, and depression causes myocardial infarction (MI) in $15 \%$ of case of Coronary Artery Disease (CAD) and are associated with higher rates of morbidity and mortality. Objective: (1) To establish the diagnosis of myocardial infarction in patients. (2) To study and correlate various psychological manifestations in these patients. Methodology: The patients for the present study were taken up from those admitted in ICCU and OPD of department of Medicine G.M.C, Ambikapur, during the study period. 50 patients were studied having CAD (Myocardial infarction). The patients were history taken in detailed \& examined (Physical and Psychiatric), investigated with reference to ECG proven myocardial infarction or cardiac enzymes proven MI. Results: We have found $46 \%$ of prevalence rate of depression in our study. Majority of patients (20\%) have mild depression (score 10-13) on (HAD-Scale), 12\% have major depression, 42\% had Anxiety. Majority of patients 26\% have mild anxiety. Only $6 \%$ have severe anxiety (score $>30$ ) in our study. Conclusion: Personality feature of CAD patients are associated with emotional as sympathetic arousal which result in increases in catecholamine as consequent increase in mobilization of free fatty acid from adipose tissue, aggregation of platelets which may precipitate MI. So, a thorough research, prevention and rehabilitation of psychologically oriented care can increase the patients sense of security and is fundamental basis of successful medical care.
\end{abstract}

Key words: Coronary Artery Disease, Intensive Coronary Care Unit, Outdoor Patients, Hamilton rating scale for depression, Hamilton Rating Scale for Anxiety, Myocardial infarction

\section{Introduction}

Coronary artery disease (MI) is as much as psychological problem as a medical one. This fact is again ascertained by present study. Finding in this study emphasized that MI (CAD) is an ultimate product of complex interaction of biological, psychological and socio-cultural factors. The factors exert their influence in precipitating and maintenance of this intractable disease. Daily life offers ample empirical evidence of an intimate relationship between the psyche and the heart. Symptoms of depression and anxiety are common following myocardial infarction. Both depression and anxiety have also been linked with and increased risk of

\footnotetext{
Manuscript received: $4^{\text {th }}$ May 2018

Reviewed: $12^{\text {th }}$ May 2018

Author Corrected: $18^{\text {th }}$ May 2018

Accepted for Publication: $22^{\text {nd }}$ May 2018
}

recurrent coronary heart disease (CHD) event following myocardial infarction (MI). Clinically depressive symptoms are found in 40 to 65 percent of patient after a myocardial and the prevalence of major depressive disorder is 20 to 25 percent. In such severe psychological and mental stress is associated with causation of myocardial infarction along with other etiological factors.

Mental stress cause dilatation of arteries but constriction of atherosclerotic coronary arteries [1]. Patient with myocardial infarction (MI) often exhibit alteration of emotional state, anxiety and depression. Sever stress and depression requires specific therapy and influences the outcome positively. 


\section{Aims and Objectives}

1. To establish the diagnosis of myocardial infarction in patients.

2. To study and correlate various psychological manifestations in these patients.

\section{Material \& Methods}

Place of study: The patients for the present study were taken up from those admitted in ICCU and OPD of department of Medicine and Psychiatry, G.M.C, Ambikapur

Type of Study: The Study is type of prospective study. It consist of assessment of the included patients and controls.

Sampling Method: We have taken randomly 50 post MI patients who have fitted according to inclusion criteria from admitted or attended in OPD of Medicine Department.

Sample Collection: For the purpose of study 50 patients were studied having CAD (Myocardial infarction).

The patients underwent detailed history taking, examinations (Physical and Psychiatric) and investigations with reference to ECG proven myocardial infarction or cardiac enzymes proven MI. Psychiatric disorders were diagnosed as per I.C.D.-10. Psychiatric evaluation was done in each case on a Semi-structured proforma and on the following three rating instruments:

(i) Life event scale, for stressful life events during last 12 months prior to the attack of MI used for study. (ii) Patients were assessed for anxiety, using Hamilton Anxiety rating scale and score was measured in each case.

(iii) Hamilton Rating Depression Scale was used for assessing the degree of depression and score was measured in each case.

\section{Inclusion criteria}

All indoor and outdoor patients of CAD (MI) in GMC, hospital Ambikapur (CG)

\section{Exclusion criteria}

1. Previous psychiatric illness.

2. More than one attack of MI.

\section{Materials}

1. Specially designed semi structured proforma for socio-demographic variables.

2. Life event scale for stressful life events.

3. Hamilton rating scale for depression.

4. Hamilton rating scale for Anxiety.

5. WHO criteria for Diagnosis of CAD - ST elevation in at least 2 consecutive leads with raised cardiac specific enzymes.

Statistical Methods: We have analyze data by using SPSS 21.0 version. We have drawn inferences as mean, SD of cases and controls group of respective variables. We have find also association between two variable by chi square test. As well as we have used t test wherever was applicable.

\section{Results}

The details were recorded on a specially prepared performed. Hamilton Depression rating scale for depression and Hamilton Anxiety rating scale for Anxiety were used for levels of Depression and Anxiety respectively and Life event scale for measurement of stressful life events in the past 12 months of occurrence of MI was used. The results are given below:

Table-1: Analysis of depression in study group.

\begin{tabular}{|c|c|}
\hline $\begin{array}{c}\text { Depression Score } \\
\text { (Hamilton Depression Rating Scale) }\end{array}$ & $\begin{array}{c}\text { Study } \\
\text { Group n( } \%)\end{array}$ \\
\hline$<10$ (Absent depression) & $27(54 \%)$ \\
\hline $10-30$ (Mild depression) & $10(20 \%)$ \\
\hline $14-17$ (moderate depression) & $7(14 \%)$ \\
\hline$>17$ (Severe depression) & $6(12 \%)$ \\
\hline
\end{tabular}

$46 \%$ patients have depression. $20 \%$ patients have mild depression. 
Table-2: Analysis of Anxiety in study group.

\begin{tabular}{|c|c|}
\hline Anxiety score (Hamilton Rating scale) & $\begin{array}{c}\text { Study } \\
\text { Group n(\%) }\end{array}$ \\
\hline$<18$ (No anxiety) & $29(58 \%)$ \\
\hline $18-24$ (Mild anxiety) & $13(26 \%)$ \\
\hline $25-29$ (moderate anxiety) & $5(10 \%)$ \\
\hline$>30$ (Severe anxiety) & $3(6 \%)$ \\
\hline
\end{tabular}

$42 \%$ patients have anxiety. $26 \%$ patients have mild anxiety.

Table-3: Analysis of MI in male \& female.

\begin{tabular}{|c|c|c|c|c|c|c|}
\hline Sex & $\mathbf{N}$ & Ant. Wall MI & Ant. Septal MI & Inf. Wall MI & Lat. Wall MI & Non STEMI \\
\hline Male & 35 & $\begin{array}{c}19 \\
(38 \%)\end{array}$ & $\begin{array}{c}4 \\
(8 \%)\end{array}$ & $\begin{array}{c}8 \\
(18 \%)\end{array}$ & $\begin{array}{c}2 \\
(4 \%)\end{array}$ & $\begin{array}{c}1 \\
(2 \%)\end{array}$ \\
\hline Female & 15 & $8(16 \%)$ & $\begin{array}{c}2 \\
(4 \%)\end{array}$ & $\begin{array}{c}4 \\
(8 \%)\end{array}$ & $\begin{array}{c}1 \\
(2 \%)\end{array}$ & 0 \\
\hline Total & 50 & $\begin{array}{c}27 \\
(54 \%)\end{array}$ & $\begin{array}{c}6 \\
(12 \%)\end{array}$ & $\begin{array}{c}13 \\
(26 \%)\end{array}$ & $\begin{array}{c}3 \\
(6 \%)\end{array}$ & $\begin{array}{c}1 \\
(2 \%)\end{array}$ \\
\hline
\end{tabular}

$54.2 \%$ male patients (19 out of 35 ) have anterior Wall MI as compared to $33.3 \%$ female patient. $11.4 \%$ male patients (4 out of 35) have antero-septal MI as compared to $13.3 \%$ female patient. $25.7 \%$ male patients ( 9 out of 35) have inferior wall MI as compared to $26.6 \%$ female patients. $5.7 \%$ male patients ( 2 out of 35 ) have lateral wall MI as compared to $6.6 \%$ female patients. Only $2.8 \%$ male patients have non-STEMI.

Table-4: Analysis of level of Depression in different types of MI.

\begin{tabular}{|c|c|c|c|c|c|c|}
\hline $\begin{array}{c}\text { Depression Score (HAM-D } \\
\text { Scale) }\end{array}$ & $\mathbf{N}$ & $\begin{array}{c}\text { Ant. } \\
\text { Wall MI }\end{array}$ & $\begin{array}{c}\text { Ant. } \\
\text { Septal MI }\end{array}$ & $\begin{array}{c}\text { Inf. Wall } \\
\text { MI }\end{array}$ & $\begin{array}{l}\text { Lat. Wall } \\
\text { MI }\end{array}$ & $\begin{array}{c}\text { Non } \\
\text { STEMI }\end{array}$ \\
\hline $\begin{array}{c}<10 \\
\text { (Absent depression) }\end{array}$ & $27(54 \%)$ & $14(28 \%)$ & $4(8 \%)$ & $2(14 \%)$ & $27(54 \%)$ & 0 \\
\hline $\begin{array}{c}10-13 \\
\text { (Mild Depression) }\end{array}$ & $\begin{array}{c}10 \\
(20 \%)\end{array}$ & $5(10 \%)$ & $1(2 \%)$ & $3(6 \%)$ & 0 & $1(2 \%)$ \\
\hline $\begin{array}{c}14-17 \\
\text { (Mod. Depression) }\end{array}$ & $7(14 \%)$ & $5(10 \%)$ & 0 & $\begin{array}{c}2 \\
(4 \%)\end{array}$ & 0 & 0 \\
\hline $\begin{array}{c}>17 \\
\text { (Severe Depression) }\end{array}$ & $6(12 \%)$ & $\begin{array}{c}3 \\
(6 \%)\end{array}$ & $\begin{array}{c}1 \\
(2 \%)\end{array}$ & $\begin{array}{c}1 \\
(2 \%)\end{array}$ & $\begin{array}{c}1 \\
(2 \%)\end{array}$ & 0 \\
\hline Total & $\begin{array}{c}50 \\
(100 \%)\end{array}$ & $\begin{array}{c}27 \\
(54 \%)\end{array}$ & $\begin{array}{c}6 \\
(12 \%)\end{array}$ & $\begin{array}{c}13 \\
(26 \%)\end{array}$ & $\begin{array}{c}3 \\
(6 \%)\end{array}$ & $\begin{array}{c}1 \\
(2 \%)\end{array}$ \\
\hline
\end{tabular}

$48 \%$ patients (13 out of 27) have depression in Anterior Wall MI. 46\% patient (6 out of 13) have depression in Inferior wall MI. 33\% patient (2 out of 6) have depression in Anterior septal wall MI. 50\% severely depressed patients (3 out of 6) belong to Anterior wall MI.70\% moderate depressed patients (6 out of 13) ) belong to Anterior wall MI. 50\% mild depressed patients (5 out of 10)) belong to Anterior wall MI.100\% patients (1 out of 1)) have mild depression in Non STEMI.

44\% patients (12 out of 27) have anxiety in Anterior Wall MI.46\% patient (6 out of 13) have anxiety in Inferior wall MI.16\% patient (2 out of 16) have anxiety in Anterior - septal wall MI. 100\% patients (out of 1) anxiety in Non STEMI.33\% patients (1 out of 3) have anxiety in Lateral wall MI.66\% severely anxious patients (3 out of 6) ) belong to anterior wall MI.80\% moderately anxious patients (4 out of 5) ) belong to Anterior wall MI.46\% mildly anxious patients (6 out of 13) ) belong to Anterior wall. 
Original Research Article

Table-5: Analysis of level of anxiety in different types of MI

\begin{tabular}{|c|c|c|c|c|c|c|}
\hline $\begin{array}{c}\text { Depression Score (HAM-D } \\
\text { Scale) }\end{array}$ & $\mathbf{N}$ & $\begin{array}{c}\text { Ant. } \\
\text { Wall MI }\end{array}$ & $\begin{array}{c}\text { Ant. } \\
\text { Septal MI }\end{array}$ & $\begin{array}{c}\text { Inf. Wall } \\
\text { MI }\end{array}$ & $\begin{array}{c}\text { Lat. Wall } \\
\text { MI }\end{array}$ & $\begin{array}{c}\text { Non } \\
\text { STEMI }\end{array}$ \\
\hline $\begin{array}{c}<18 \\
(\text { Absent Anxiety) }\end{array}$ & $29(58 \%)$ & $\begin{array}{c}15 \\
(30 \%)\end{array}$ & $5(10 \%)$ & $\begin{array}{c}7 \\
(14 \%)\end{array}$ & $\begin{array}{c}2 \\
(4 \%)\end{array}$ & 0 \\
\hline $\begin{array}{c}18-25 \\
\text { (Mild Anxiety)) }\end{array}$ & $\begin{array}{c}13 \\
(26 \%)\end{array}$ & $6(12 \%)$ & $\begin{array}{c}1 \\
(2 \%)\end{array}$ & $\begin{array}{c}4 \\
(8 \%)\end{array}$ & $\begin{array}{c}1 \\
(2 \%)\end{array}$ & $1(2 \%)$ \\
\hline $\begin{array}{c}20-30 \\
\text { (Mod. Depression) }\end{array}$ & $5(10 \%)$ & $4(8 \%)$ & 0 & $\begin{array}{c}1 \\
(2 \%)\end{array}$ & 0 & 0 \\
\hline$>30$ & $3(6 \%)$ & $\begin{array}{c}2 \\
(4 \%)\end{array}$ & 0 & $\begin{array}{c}1 \\
(2 \%)\end{array}$ & 0 & 0 \\
\hline (Severe Anxiety) & $\begin{array}{c}\mathbf{5 0} \\
(\mathbf{1 0 0} \%)\end{array}$ & $\begin{array}{c}\mathbf{2 7} \\
\mathbf{( 5 4 \% )}\end{array}$ & $\begin{array}{c}\mathbf{6} \\
(\mathbf{1 2} \%)\end{array}$ & $\begin{array}{c}\mathbf{1 3} \\
(\mathbf{2 6} \%)\end{array}$ & $\begin{array}{c}\mathbf{3} \\
(\mathbf{6 \%})\end{array}$ & $\begin{array}{c}\mathbf{1} \\
\mathbf{( 2 \% )}\end{array}$ \\
\hline
\end{tabular}

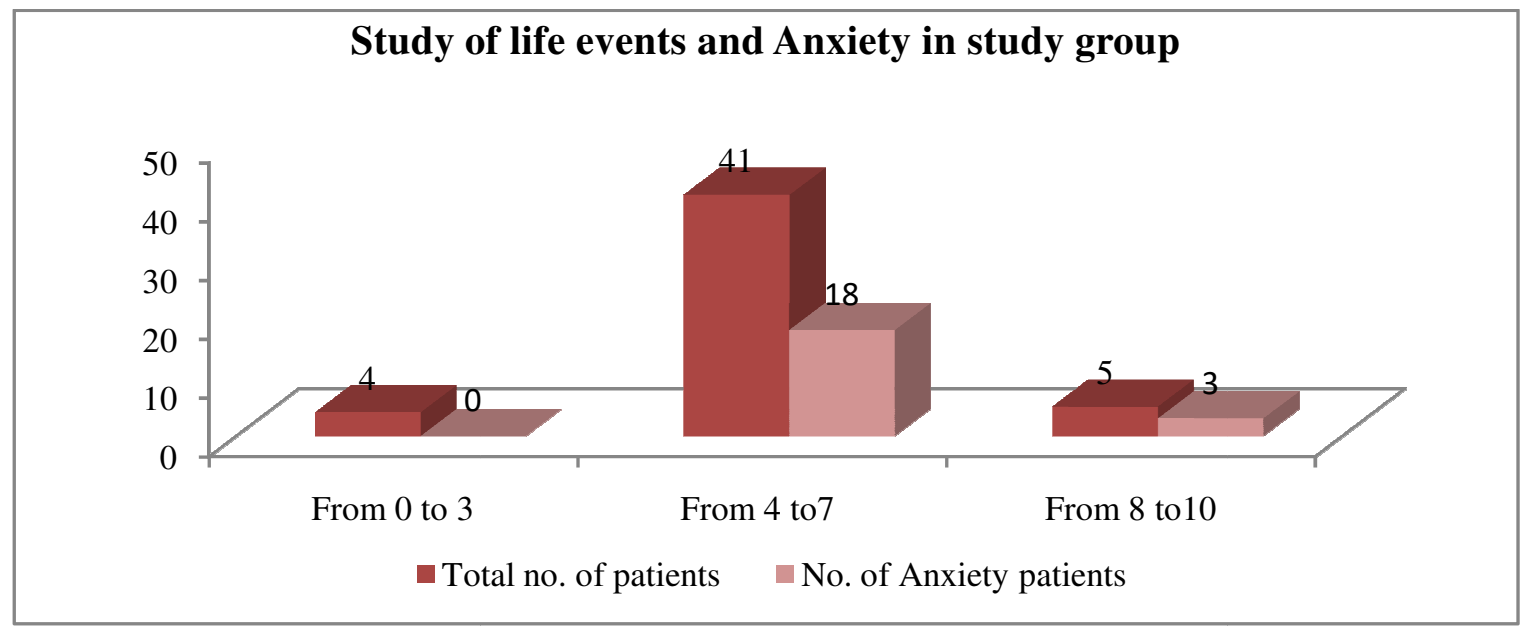

Graph-1: Showing that life events and Anxiety in study group

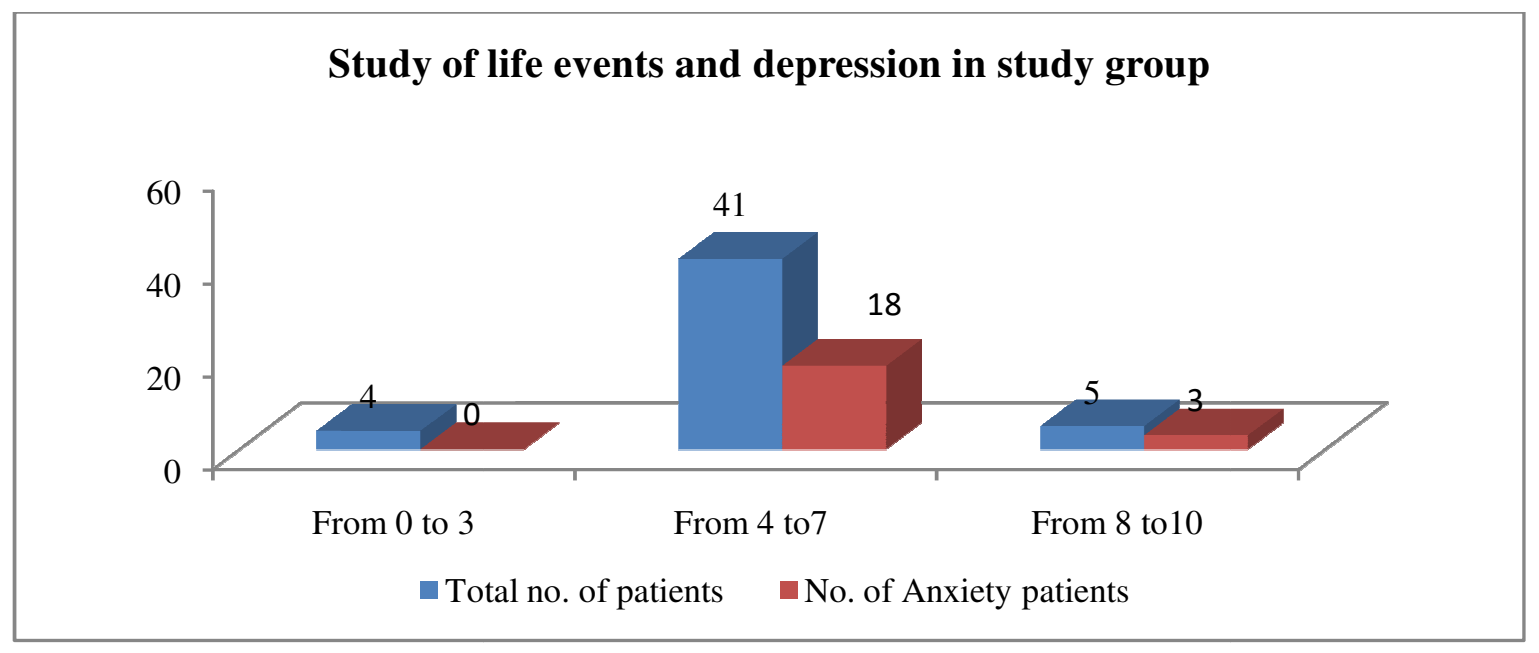

Graph-2: Showing life events and depression in study group

Majority of patients (82\%) have life events between (4-7) and 54\% have life events score between (100-200). 42\% of patients having depression. $91.3 \%$ of depressed have life events between 4-7 and patients having anxiety (63\%) have life events between 4-7 and also patients having anxiety (24\%) have score between (201-300). Only one patients have highest score of 305 and total events 10, anxiety score of 32, depression score of 24 on Hamilton rating scale. 


\section{Discussion}

In our study we found $46 \%$ prevalence rate of depression in post myocardial infarction patients which is higher than previous study. Other authors have also reported high prevalence $20 \%$ to $31 \%$ in their study $[2,3]$. Another study they found as $65 \%$ of depression in CAD patients [4]. Majority of patients $20 \%$ have mild depression \& 6 patients out of 23 (28\%) have major depression. (Cardiology review 2002) found depression as independent risk factor in CAD patients, which may be explained by association between mood disturbance and adverse outcome, disturbance in autonomic tone, platelet activation and aggregation which may cause CAD [5].

Present study showed $42 \%$ prevalence rate of anxiety disorder in CAD patients which is supported by various authors [6][7][8]. Anxiety increase sympathetic tone which cause increase secretion of Catecholamines and Control lead to myocardial hypoxia, increase in cardiac output, heart rate and blood pressure, may precipitate myocardial infarction (MI).

In our study, majority of patients are males in both study and control group, $28 \%$ of patients, having depression are males as compared to $18 \%$ females and $30 \%$ males have anxiety as compared to $12 \%$ in females. Overall probable ratio of anxiety and depression is higher in females. 14 out of 35 patients in males $(40 \%)$ have depression as compared to 9 out of $15(60 \%)$ in females in depressed and 15 out of 35 $(42.85 \%)$ in males have anxiety as compared of 6 out of $15(40 \%)$ in female patients which is supported by study, who found females have more depression and anxiety than males in CAD patients [9].

In our study, Majority of patients are in social class II $16 \%$ \& $(34.8 \%)$ depressed are in class II. Only 4\% was in lower social class IV having depression, this may be due to the difference in sample size, this is also supported by study which is socio economic disadvantages are related to increased morbidity and lower social class have increased incidence of CAD with more anxiety and depression [10].

Majority of patients $28 \%$ have no anxiety (score $<18$ ); $42 \%$ of patients have anxiety in study group. $44 \%$ patients (42 out of 27) have anxiety in anterior wall MI. Only one patient have non STEMI and have both anxiety and depression. 3 patients $(6 \%)$ have severe anxiety (score $>30$ ) in which 2 patients $(4 \%)$ in Anterior wall MI and 1 patient (2\%) in interior wall MI. We have found that in another studies have severe depression is risk factor for $\mathrm{CAD}$ [11] \& $8 \%$ patients show moderate anxiety 6 out of 38 patients $(15.8 \%)$ in study show depression in his study [12]. Psychosocial factors may contribute to cardiovascular pathology by way of neuroendocrine and neural pathways. The limbic system, the catecholamines play particularly influential roles in mediating the effects on the heart and blood vessels. Psychological factors related to interpersonal relationship and those reflecting personality style may influence the occurrence and outcome of cardiovascular disease.

Once the cardiovascular pathology is preset intense emotional arousal can trigger or exacerbate symptoms and tend to exert a feedback effects on emotional arousal such as anxiety and depression and a viscous cycle may develop. For example, a patient who is given a diagnosis of CAD becomes frightened and increases his physical activity, smoking or eating in an attempt to relieve the fear. Various cardiovascular responses may be learned as a result of operant conditioning become a person's habitual of specific mode of autonomic response to arousing symbolic stimuli. The primary and secondary prevention of CAD involve the use of strategies aimed at modifying behavior pattern. Various levels of prevention consist of health Education screening of risk factors, control hypertension and rehabilitation by behavioral methods. Behavioral methods involve cardiac stress management programme, which is aimed at two objectives; Stress management training and change of habitual behavior. Stress management training involving teaching the person how to relax, identify situations of competitiveness, time pressure, achievement motivations and hostility.

Early detection of post MI depression and treatment with SSRI have shown to decrease mortality and fatal rhythmic disturbance. But major depression is rarely deducted and treated in cardiology setting. There is strong evidence that stress can trigger cardiac events psychological and behavioral interventions targeting distresses itself appear to hold good promise they found stress management reduce the risk of CAD [13].

In our study, the trend for anxiety, majority (24\%) having anxiety have score between 201-300. None is having score above 300 . So, majority of patients having depression and anxiety have major life events between 4-7 and score between 200-300. 


\section{Conclusion}

Personality feature of CAD patients are associated with emotional as sympathetic arousal which may precipitate MI. From this study it can be logically concluded that with the beginning of diagnosis, there are a series of predictable personal crisis in the subsequent course of CAD. Thus it should become a part of the prescription of every physician to educate the newly diagnosed one about various other behavioral and psychological consequences [14].

\section{Funding: Nil, Conflict of interest: None Permission of IRB: Yes}

\section{References}

1. Rozanski A, Blumenthal JA, Kaplan J. Impact of psychological factors on the pathogenesis of cardiovascular disease and implications for therapy. Circulation. 1999 Apr 27; 99 (16):2192-217.

2. Ter Horst GJ et al. Central autonomic control of the heart angina and pathogenic mechanisms of post myocardial infarction depression European Journal of Morphology. 1999; 37(4-5) : 257-66.

3. Paterniti S et al. Sustained anxiety and 4- year progression of carotid atherosclerosis, thrombosis and vascular biology. 2001; 21(I) : 136-41.

4. Mittleman MA, Maclure M, Sherwood JB, Mulry RP, Tofler GH, Jacobs SC, Friedman R, Benson H, Muller JE. Determinants of Myocardial Infarction Onset Study Investigators. Circulation. 1995 Oct 1;92(7):1720-5.

5. Heather S.Lett et al. Depression as independent factor inCAD patients.Cardiology1983;70:308-16, 2002

6. Thiel HG, Parker D, Bruce TA. Stress factors and the risk of myocardial infarction. J Psychosom Res. 1973 Jan;17(1):43-57.
7. Barry J. et al. Frequency of ST segment depression produced by mental stress in stable angina pectoris from coronary artery disease AM J. Cardial. 1998; 61(13) : 989-993

8. Kane FJ Jr. et al. Chest Pain and anxiety disorder. Tex Med. 1990 Jul;86(7):104-10.

9. O. Brien J.L. et al. Comparison of anxiety assessments between clinician and patients with acute myocardial infarction in cardiac critical care units. Am J Crit Care. 2001 Mar;10(2):97-103.

10. Rasik $\mathrm{CH}$ et al. The impact of religious orientation in conjugal bereavement among older adults. Int $\mathbf{J}$ Aging Hum Dev. 2011;72(2):137-54.

11. Lavoie KL, Fleet RP. The impact of depression on the course and outcome of coronary artery disease: review for cardiologists. Can J Cardiol. 2000 May; 16 (5):653-62.

12. Ulla Edell Gustafsson et.al. Sleep, arousal and health-related quality of life in men and women with coronary artery disease. Journal of Clinical Nursing, 2011; 20(19-20), 2787-2801.

13. Bluementhal JA et al. Mental Stress induced ischemia in the laboratory and ambulatory ischemia during daily life. Circulation. 1995 Oct 15; 92 (8): 2102-8.

14. Bluementhal JA et al. Stress management and exercise treatment in cardiac patients with myocardial ischemia. Arch Intern Med. 1997 Oct 27; 157 (19): 2213-23.

\section{How to cite this article?}

Singh S, Kanwar G, Paikra S, Pandey S.Psychological manifestations in post myocardial infraction patients. Int J Med Res Rev 2018;6(05):237-242. doi:10.17511/ijmrr. 2018.i05.01. 